\title{
EXPLORANDO AS RELAÇõES ENTRE SEGURANÇA, CONSTITUIÇÃO CONSTITUCIONALISMO EUROPEU ${ }^{1,2}$
}

\section{EXPLORING THE RELATIONSHIPS BETWEEN SECURITY, CONSTITUTION AND EUROPEAN CONSTITUTIONALISM}

Enrique Guillén López ${ }^{3}$

Resumo: Com o presente artigo, pretende-se explorar as relações entre segurança, constituição e constitucionalismo europeu. A análise mostra a necessidade de revelar a profunda densidade e complexidade do conceito de segurança e a importância de adequá-lo a modelos constitucionais que já não são exclusivamente estatais. No âmbito regional europeu, as respostas constitucionais nacionais devem ser consideradas como respostas parciais no quadro de uma política europeia de segurança e direitos.

Palavras-chave: Segurança. Constituição. Direitos. Constitucionalismo europeu. União Europeia.

\begin{abstract}
This contribution aims to carry out an exploration of the relations between security, constitution and European constitutionalism. The analysis shows the need to reveal the profound density and complexity of the concept of security and the importance of fitting it into constitutional models that are not exclusively on the state-level. In the european regional sphere, therefore, national constitutional responses should be considered as partial responses within the framework of a European policy of Security and rights.
\end{abstract}

Keywords: Security. Constitution. Rights. European constitutionalism. European Union.

Recebido em 6 de fevereiro de 2020 Aceito em 20 de abril de 2020

\section{Introdução. 0 paradigma}

Com a presente contribuição se pretende analisar as relações entre Segurança, Constituição e Constitucionalismo europeu. A relação entre os dois primeiros nos remete a problemas de fundamentos que hoje apenas admitem uma resposta nos limites do terceiro: o constitucionalismo europeu.

A aproximação que se realiza tem como paradigma uma teoria geral da constituição e dos direitos fundamentais (já não cabe uma sem a outra), teoria que se refere a um arquétipo, o constitucionalismo, como um constructo elaborado a partir de experiências constitucionais primárias dos Estados-nação, em sua dimensão histórica e atual. Essas experiências relacionam-se com o constitucionalismo em uma complexa relação já que de forma simultânea o nutrem e são

\footnotetext{
1 Este trabalho foi realizado no âmbito do projeto de investigação "Direitos Fundamentais ante às crises econômicas e de segurança num quadro constitucional fragmentado" DER2016-77924-P, financiado pelo Ministério da Economia e Competitividade (MINECO).

2 Traduzido por Natálie Vailatti; Especialista em Direito Público e Privado: Direito Material e Processual pela Universidade do Oeste de Santa Catarina (Unoesc); Advogada e Assistente Administrativo na Universidade do Oeste de Santa Catarina (Unoesc/Chapecó); https://orcid.org/0000-0002-7072-0316; natalievailatti@gmail.com

Robison Tramontina; Doutor em Filosofia pela Pontifícia Universidade Católica do Rio Grande do Sul (PUC/RS); Coordenador do Programa de Pós-graduação em Direito na Universidade do Oeste de Santa Catarina (Unoesc/Chapecó); https:// orcid.org/0000-0002-1852-4983; robison.tramontina@unoesc.edu.br

3 Doutor em Direito pela Universidade de Granada, Espanha; Professor de Direito Constitucional na Universidade de Granada, Espanha; Plaza de la Universidad, s/n., 18001, Granada, Espanha; https://orcid.org/0000-0003-3972-9002; enriqueg@ugr.es
} 
nutridas por ele. Portanto, não se trata apenas de um processo unidirecional em que as normas fundamentais estatais operam como fonte para extrair um tipo ideal de constitucionalismo, mas sim da elaboraração de novas regras constitucionais que devem superar a desvantagem daquelas que estiveram em sua origem. $\bigcirc$ Constitucionalismo, originariamente, serviu como fundamento normativo pensado exclusivamente para resolver conflitos entre só Estados-Nação soberanos.

Devemos salientar que este constitucionalismo é evidentemente um conceito doutrinário, entendido como um tratamento articulado de princípios e regras levados a cabo pelos acadêmicos de acordo com a pretendida ordem e rigor do método científico.

Entretanto, também já é uma realidade que tem um referente preciso, tangível, que o afasta da mera elocubração teórica. É o que pode ser encontrado, pelo menos em marcos regionais delimitados, regras jurídicas, ordenamentos, as quais se pode enfaticamente atribuir força compulsória frente às práticas nacionais que não as respeitam. ${ }^{4}$ Tanto é assim que as experiências constitucionais internas, nestes casos, deixam de sê-las porque a nova realidade constitucional tem imposto a sua degradação em atos de desenvolvimento não suficientemente adequados com o paradigma no qual elas são julgadas. ${ }^{5}$

Não é outra coisa o constitucionalismo, no âmbito do Conselho da Europa, senão um paradigma de resolução jurisdicional de conflitos baseados na garantia de direitos ${ }^{6}$ que a partir das diferentes respostas estatais as quais se concede capacidade resolutiva originária (princípio da subsidiariedade) erige um consenso europeu sobre as liberdades fundamentais com uma entidade autônoma. $\bigcirc$ Tribunal Europeu de Direitos Humanos atribuiu-se um papel fundamental na elaboração de uma ordem pública europeia, como garante a Convenção de Roma. ${ }^{7}$ Trata-

4 Sobre a qualidade coercitiva, não tanto da norma como dos ordenamentos, seguem sendo ilumindoras as páginas de Balaguer Callejon (1991, p. 98 e ss.).

5 Cfr. STEDH, de 22 diciembre 2009 (Gran Cámara), Sejdic' y Finci c. Bosnia Hercegovina, sobre a violação da proibição de discriminação por parte de alguns requisitos da Constituição da Bósnia-Herzegóvina que previam cotas para grupos étnicos na ocupação dos cargos oficiais do Estado. Posteriormente, STEDH Alajos Kiss c. Hungría, de 20 mayo 2010, observou que a provisão da Constituição do Estado demandava a restrição de maneira indiscriminada ao direito de voto de deficientes mentais é contrária ao direito de participação.

6 E a partir daí, pela força expansiva dos direitos é capaz ao processo de eleição de forma integra das políticas públicas de um Estado-membro. Considere, por exemplo, a forte rejeição de Estrasburgo de certas práticas dos Estados-Membros. De acordo com STEDH Volkov c. Ucrânia de 9 de janeiro de 2013 (esta sentença afirma, nada menos, que o sistema de responsabilidade disciplinar dos juízes na Ucrânia não assegura suficientemente a independência do poder judiciário frente ao restante dos poderes).

7 Loizidou c. Turquía, 23 de marzo de 1995. Reiterado, por exemplo, na sentença de Al-Skeini y otros c. Reino Unido de 17 de julio de 2011. Mais além vão os pronunciamentos do juiz Pinto de Albuquerque no voto confidencial simultâneo Hajiyev, Pejchal y Dedov) ditado na sentença Dulimi y Montana Management Inc. C. Suiza de 21 de junio de 2016, grifo nosso: "59. Le Conseil de l'Europe est un ordre juridique autonome fondé sur des accords et sur une action commune dans le domaine économique, social, culturel, scientifique, juridique et administratif ainsi que dans la sauvegarde et le développement des droits de l'homme et des libertés fondamentales (article 1, paragraphe b, du Statut du Conseil de l'Europe de 1949). Avec plus de 217 traités, l'ordre juridique de cette organisation internationale a à son sommet un traité international, la Convention européenne des droits de l'homme qui a un effet direct et supra-constitutionnel sur les ordres juridiques nationaux des États membres du Conseil de l'Europe[112]. Étant plus qu'un simple accord multilatéral sur des obligations réciproques d'États parties, la Convention crée des obligations pour les États parties envers toutes les personnes et entités privées relevant de leur juridiction. Avec son rôle de vecteur de transformation proclamé avec emphase dans le préambule qui lui donne vocation à construire une union plus étroite des États européens et pour développer les droits de l'homme sur une large base paneuropéenne, la Convention n'est ni subordonnée aux règles constitutionnelles nationales, ni aux prétendues règles supérieures du droit international, puisque c'est le droit suprême du continent européen[113]. Dans la hiérarchie de normes interne au Conseil de l'Europe lui-même, le droit des Nations unies équivaut à tout autre accord international et est subordonné à la primauté de la Convention en tant qu'instrument constitutionnel de l'ordre public européen[114]. 
se de um conceito em construção permanente; de uma expressão constantemente atualizada do constitucionalismo Europeu, diferenciável e diferenciado da ordem pública dos Estados-membros do Conselho da Europa. Em resumo, as aproximações que devem ser feitas das grandes questões que o direito constitucional regula, especialmente a garantia de direitos e a atuação do complexo institucional que deve tornar efetiva a divisão de poderes, deve se pensar tanto na doutrina que se deve incorporar ao constitucionalismo como na realidade jurídica sempre em reelaboração.

Contudo, o direito construído pelo TEDH no marco da Convenção para servir de parâmetro, não só bebe dos modelos constitucionais dos Estados-Membros, mas também recorre a outros ordenamentos com os quais compartilham pressupostos materiais. No caso, por exemplo, de sentenças como M.C. c. Bulgária, de 4 de dezembro de 2003, se examinam os requisitos reunidos na legislação penal para responder aos delitos contra a liberdade sexual (especialmente a violação), considerando modelos como o norte americano. ${ }^{8} \mathrm{Um}$ comentário, é precisamente nos Estados Unidos, em um estado muito embrionário, que se utiliza critérios constitucionais extranacionais, isto é de um constitucionalismo extra ordinem para resolver controvérsias como a da constitucionalidade das relações homossexuais consentidas entre adultos (cf. Lawrence vs. Texas ${ }^{9}$ ).

Isso quer dizer que cabe a possibilidade de construir um discurso geral com o objetivo de servir de resolução para controvérsias definitivas internas (especialmente em direitos, mas não apenas). ${ }^{10}$

Voltando ao âmbito Constitucional Europeu, esta coexistência de constitucionalismo nacional e supranacional se integra naquilo que vem sendo chamado de constitucionalismo multinível, ${ }^{11}$ que é o terreno não apenas propício, mas necessário para a indagação acadêmica. Sendo

60. De là découle la nature de la Cour en tant que Cour constitutionnelle européenne, dont les arrêts ont un effet erga omnes res interpretata qui va au-delà de leur effet inter partes res judicata, ainsi qu'un effet prescriptif puissant qui va bien au-delà de ses effets purement déclaratoires mentionnés fréquemment. Les procédures d'arrêts pilotes et quasi pilotes sont typiquement des instruments de contrôle constitutionnel, qui jouent un rôle central dans le redressement de dysfonctionnements du droit national ou la non-réglementation par le législateur en présence de dysfonctionnements systémiques[115]. Si besoin est, dans le dispositif de ses arrêts, la Cour exerce un pouvoir d'annulation indirect à travers des injonctions faites en vertu de l'article 46 en demandant à l'État défendeur à réviser ses lois, règlements administratifs et pratiques. Même si elle ne l'a pas encore utilisée, la Cour a également la compétence pour exercer une action en violation (article $46 \int 4$ de la Convention). Finalement, elle a compétence sur sa propre compétence (Kompetenzkompetenz), qui n'exclut pas, en cas de blocage politique de la procédure d'exécution et de l'action en violation au niveau du Comité des ministres, qu'elle accepte de jouer un rôle de supervision concernant l'inexécution ou l'exécution incomplète d'un arrêt de la Cour, même en l'absence d'une telle action en violation. C'est enfoncer une porte ouverte aujourd'hui que de dire que le mécanisme d'exécution essentiellement intergouvernemental a radicalement changé de nature de par le rôle prépondérant que la Cour elle-même joue dans la garantie de l'efficacité du système de protection des droits de l'homme[116]. Le Conseil de l'Europe peut ainsi avancer une forte revendication constitutionnelle."

8 Par. 158: "Dans les juridictions de common law, en Europe et ailleurs, la notion de force physique a disparu des textes de loi et/ou de la jurisprudence (veja os parágrafos 98, 100 et 138-147 acima que trata de sistemas jurídicos da Irlanda, Reino Unido e Estados Unidos e de outros países). Le droit irlandais déclare expressément que le consentement ne peut être déduit de l'absence de résistance." (parágrafo 98 acima).

9 Lawrence v. Texas (2003) 123 S. Ct. 2472. Cf. o texto em espanhol da sentença e uma adequada contextualização em Beltrán de Felipe y González García (2006, p. 662-679).

10 Para tal objetivo atende a enorme abertura de pensamento de Peter Häberle que vai alicerçar a ponderação do método comparativo como quinto método de interpretação Cfr. P. HÄBERLE, Rechtsvergleichung im Kraftfeld des Verfassungsstaates. Methoden und Inhalte, Kleinstaaten und Entwicklungsländer, Duncker \& Humblot, Berlin, 1992, pp. 27-44. Uma exposição de valores que pondera a relevância e o que representa a teoria de Häberle pode ler-se em Balaguer Callejón (2010, p. 189-208).

11 Pernice (2002). Esta teoria tem ecos da construção de Peter Häberle referindo-se às constituições nacionais como Constituições parciais. Ver, em espanhol, El constitucionalismo universal desde las constituciones parciales nacionales e internacionales: siete tesis, em Balaguer Callejón (2014, p. 41-50). 
assim, não é imaginável escrever exclusivamente numa perspectiva exclusivamente nacional. Somente se podem examinar juridicamente os conceitos que marcam o direito constitucional a partir de uma visão que escape da lógica estatal (de cada estado). Esta é uma consequência inevitável da crise do conceito de soberania. Posto isso, se deve pensar uma reordenação harmonizada (não necessariamente unificadora) de todos os conceitos com os quais tem sido associado o constitucionalismo, e entre eles estão alguns como o da segurança.

No entanto, este constitucionalismo, que sempre teve sérias dificuldades em avançar, encontra-se hoje em uma situação crítica, devido fundamentalmente à falta de confiança que se instalou em nossas sociedades. Efetivamente, um dos conceitos que podem ser utilizados para distinguir os períodos normais daqueles de crise regressiva é o da confiança. Em segundos, se quebra a conexão entre os sujeitos de direitos, instituições e o ordenamento jurídico, o que prejudica a capacidade de controlar o poder. Hoje, essa confiança, este otimismo, está em retirada porque o panorama é certamente sombrio. Os direitos, as instituições e os ordenamentos não acreditam serem capazes de conter a força de certos poderes, que são agora fundamentalmente privados, que estão redefinindo - em seu próprio benefício - pela força dos feitos nos âmbitos constitucionalmente fundamentais: a economia e os processos de comunicação. Isto resulta que o interesse geral é protegido somente nas esferas que a estrutura pública-jurídica tinha estabelecido sua existência: processos eleitorais (com o deturpação da vontade cidadã) e distribuição de riqueza (concedendo status de normalidade à especulação financeira) (BALAGUER CALLEJÓN, 2018). Constatar essa crise de confiança, esse horizonte preocupante para as categorias clássicas de constituição e constitucionalismo, serve para nos antecipar uma crise ainda mais aguda, e se generaliza a impressão e o sentimento, de que não estamos seguros.

\section{Segurança e direito constitucional}

A pessoa quer sentir-se segura. É óbvio que os seres humanos viveram e evoluíram em um contexto em que eram frequentes os confrontos físicos de resultado imprevisível, a sujeição às forças naturais capazes de aniquilar sua vida ou destruir o lugar que trabalhosamente tinha construído para se abrigar. A vida tem sido uma luta pela sobrevivência e, ainda, continua sendo. Não é porque alguém dispõe de uma casa confortável que ele não está sujeito a sofrer uma doença capaz de reduzir ao vazio tudo aquilo que se dedicava com atenção antes de ouvir o resultado fatal de exames médicos.

A pessoa, portanto, queria estar segura. ${ }^{12}$ Queria estar a salvo de situações imponderáveis. Conseguiu, por exemplo, estar relativamente convencida de que as transações comerciais realizadas não envolviam o enriquecimento ilícito da outra parte quando se instaurou o sistema métrico

12 Ortega y Gasset (2011) apontam: "Nos movemos em busca de uma segurança radical, nós necessitamos porque somos temporariamente, o que já fomos presenteados com o nascimento no berço, é uma inseguridade radical." 
decimal; ${ }^{13}$ tem conseguido nos últimos dois séculos que, durante certos períodos de tempo poderia desfrutar de algo chamado liberdades, o que o permitiu sair na rua, contando com o retorno para o jantar; professou a religião que iria se reconfortar sem pensar que a chave da casa que iria deixar aos herdeiros seria como um mero símbolo da morada para sempre perdida; poder criticar o governo sem perder por isso a sua propriedade.

No entanto, não foi isenta de guerras terríveis. Aniquilações devastadoras e massivas reduziram a cinzas todas essas expectativas. As guerras são o ponto zero de segurança. Não tem uma garantia mínima: nem a sua vida, nem a vida dos teus, e nem a dos inimigos. A preservação da existência dos próximos depende da intensidade com que você ameaça os outros.

O desejo de invocar a insegurança é tendêncial e inevitavelmente crescente. O cessar-fogo não basta. Queremos, então, proteger-nos de qualquer coisa que não possa nos permitir assumir o controle de nossas vidas e vemos a necessidade de criar estruturas de redução de risco onde não somos autossuficientes. E assim, o conceito de auto-suficiência torna-se um elemento essencial para determinar a identidade das estruturas que são reduzidas a insegurança. Nas sociedades fundadas na ideia de um indivíduo capaz, por si só, de tecer o destino não é fácil pensar em sistemas públicos de saúde, desemprego, pensionistas e até mesmo intervenção puramente individual nas tarefas de manutenção da segurança pública. ${ }^{14} \mathrm{~A}$ intervenção pública em todos estes setores, no entanto, tem sido evidentemente imposta ao continente europeu, especialmente durante os "trinta anos felizes" após a Segunda Guerra Mundial (JUDT, 2008): o europeu problemático, as mulheres que ficaram na retanguarda para receber o que chegava, exigiram dos Estados, que tinham enviado seus homens e seus filhos, a recompensa mínima por cuidarem da sua segurança.

A Europa democrática vive, então, um período inigualado e provavelmente inigualável. É o estado da busca existencial, o qual a doutrina alemã chama Daseinsorge. Um estado que cuida, que assiste, que protege, ${ }^{15}$ que se manifesta amparando as pessoas em suas necessidades coletivas (infraestrutura, educação, prestação de saúde aos desempregados, aposentadas, segurança cidadã), tentando levar inclusive a segurança para um âmbito não pensado como o de mercado (que depende da liberdade dos

\footnotetext{
13 Em similar sentido: "No curso da transação da sociedade agrária para a sociedade mercantil surgiu uma nova necessidade, com fundamento económico, de segurança. Partiu dos comerciantes que haviam se estabelecido e se dirigia à venda de bens e mercadorias em mercados maiores que os mercados fortemente limitados especialmente dispersos e colocados à disposição dos numerosos senhores medievais. A contribuição da necessidade de segurança foi fundamentada no desenvolvimento económico e o Estado de Direito que destacamos a seguir. A respeito, deve se clarificar, em especial a importância da segurança jurídica interna para o desenvolvimento de um país e a garantia da segurança jurídica como uma tarefa estatal básica." (LÖSING, 2002, p. 274).

14 Devemos contemplar, eu compreendo, o significado da segunda emenda da Constituição norte-americana que, como é sabido, reconhece o direito de portar armas da seguinte forma: "É necessário uma milícia bem ordenada para a segurança de um estado livre, não se violará o direito das pessoas de possuir e portar armas." (CONSTITUIÇÃO DOS ESTADOS UNIDOS, 1789).

15 Assim, pode ser entendido tão bem porque ocasionalmente é manchado como "paternalista" (maternalista eu diria e não exatamente impedido por qualquer obrigação de exatidão política da linguagem) para este estado do outro lado do Atlântico. Pode ser interessante notar a controvérsia jurídica causada nos EUA por certas ações públicas destinadas a proteger a segurança dos cidadãos, como a obrigação do capacete (MOSER JONES; BAYER, 2007).
} 
diferentes intervenientes envolvidos). O estado intervém no processo econômico, ${ }^{16}$ planeja e, assim, reduz a incerteza, o medo, diante de uma desvalorização das condições materiais de vida das pessoas ou de seus descendentes. ${ }^{17}$ Todos as quebras devem ser controladas e se desenham estruturas nacionais, internacionais e supranacional para elas. ${ }^{18}$ Apenas a ameaça da guerra nuclear e, mais recentemente, as catástrofes ambientais ${ }^{19}$ pairam sobre a segurança ${ }^{20}$ permitindo a análise doutrinária que, certamente paradoxal - se se observa a questão com a perspectiva histórica que estamos empreendendo - definem com sucesso esta sociedade como "a sociedade do risco", ${ }^{21}$ a que nós devemos responder unindo a força renovada a um velho princípio: o princípio da responsabilidade (JONAS, 1995).

Certamente, como Beck consegue avaliar, esse risco surge da insegurança criada como resultado da crise do Estado social, que nada mais é do que a crise em uma série de direitos que conseguiram instalar uma previsibilidade aceitável em amplas camadas da população. Se a segurança é o resultado de direitos, a menor garantia de certos direitos cria incerteza. E, a análise de Beck, não contava que assim que o século XXI começasse, sofreríamos uma crise econômica como não havia sido experimentada desde a década de 1930, e uma série de ataques terroristas orquestrados para produzir o maior número de mortes entre a população em geral. Consequentemente, a UE estabeleceu-se no paradigma que sempre foi utilizado para superar a insegurança: a excepcionalidade. ${ }^{22}$

16 Poderíamos considerar em que medida a fechada (POPPER, 1957) utopia marxista com sistema de produção total e cientificamente planejada é uma tentativa de acabar com a mudança; uma tentativa de estabelecer de uma vez por todas a ordem correta do mundo (isto se vê em bases justas, diria o marxismo) de modo as pessoas não estariam expostas aos grandes perigos do que é puramente aleatório. A utopia da previsibilidade completa: do berço ao túmulo.

17 Neste processo de afirmação contínua da segurança aparece neste momento com substantividade o papel dos descendentes, de que herdarão a terra quando nós não estaremos mais. Certamente também se relaciona com a avaliação pela primeira vez, como vamos apontar, do risco ambiental, bem como a eventualidade de uma terceira - e definitiva - Guerra Mundial, travada com armas atômicas.

18 O abandono de direitos mediante a criação da jurisdição constitucional e organizações internacionais como o Conselho da Europa. O abandono econômico através de políticas keynesianas que geram a paz social e a criação de estruturas antiprotetivas como da EU.

19 Representa um trampolim da usina nuclear de Chernobyl na Ucrânia.

20 Não podemos esquecer, no entanto, a influência dos vários atentados terroristas que recordaram a Europa da eventual fragilidade das suas estruturas políticas (os terrorismos do Baader Meinhoff na Alemanha, das Brigadas Vermelhas na Itália) e a sua exposição aos conflitos simultaneamente territorial e religioso (especialmente as ações dos terroristas palestinianos).

21 Título do trabalho muito influente do sociólogo alemão Ulrich Beck em 1986. Esta definição de sociedade causa ao risco uma dimensão constitutiva, que claramente tem um impacto significativo na formação do direito como um subsistema social. A deriva favorável à limitação das liberdades resulta também do fato de a proporcionalidade, como princípio, ser pouco suscetível à preservação das liberdades quando são confrontados com um grande valor, como a segurança. Grimm (2006, p. 208) tem assim visto: "Mas a previsão de risco mais recente e urgente também ameaça reduzir a máxima da proporcionalidade. Como critério relativo, faz a conveniência de uma restrição de direitos fundamentais dependente da dimensão do perigo a ser combatido: se for suficientemente grande, pode reduzir drasticamente o limite de intervenção em outros direitos fundamentais. Por conseguinte, é concebível na sociedade de risco que qualquer critério específico apareça, de maneira precisa e apropriada, com uma carga proporcionalmente insignificante a favor de um bem jurídico de grande valor, de modo que no conjunto a liberdade perde em prol da segurança. A Constituição é, portanto, novamente encontrada fora da vida social, sem que tenha existido qualquer modificação textual." É precisamente a última sentença deste trabalho sugestivo que nos coloca diante de um dos principais empreendimentos desta obra, que é evitar essa marginalidade da Constituição no campo da segurança.

22 A excepcionalidade econômica sobrevoa, por exemplo, sobre todo o caso Gauweiler, tanto na opinião do advogado-geral Cruz Villalón como no do TJ no seu acórdão. Conforme STJUE Asunto C-62/14 Gauweiler y otros. No que se refere à excepcionalidade e à segurança dos cidadãos, deve-se considerar a vigência dos 719 dias de Estado de urgência na República Francesa (CERDÁ GUZMAN, 2017). 
Nesse contexto, o direito, que não pode deixar de atender às necessidades humanas, como instrumento que é de resolução pacífica de seus conflitos, deve integrar entre seus elementos as pretensões de segurança dos sujeitos. Em suma, os sujeitos de forma autônoma e coletiva que somos, no sentido tradicional, a fonte de direito democrático (o povo como o titular da soberania), temos de racionalizar o conceito, limpá-lo, estabelecer mecanismos para a sua garantia e limites para seu utilização espúria. ${ }^{23}$

É aqui onde é convocado com urgência o o constitucionalismo. Este trabalho tentará abordar alguns dos muitos aspectos e relacões que estão entre os termos segurança e constitucionalismo. Ambos os termos não são redutíveis a esquemas rígidos e imutáveis. Nem a segurança refere-se sempre à mesma coisa, nem o constitucionalismo é apresentado com o mesmo conteúdo e âmbito de referência idêntico, como vimos nas primeiras páginas. $\bigcirc$ constitucionalismo e a segurança têm sido companheiros invariáveis na jornada que os levou até o momento atual e seu pareamento não parece estar próximo do fim. Não há constitucionalismo que não conta com as necessidades de segurança, que são muitas e têm âncoras diferentes: o Estado, a Lei, a Pessoa.

O projeto constitucional segue podendo ser definido conforme o artigo 16 da Declaração dos Direitos do Homem e do Cidadão (1789), isto é, pelo controle do poder e pela garantia dos direito. ${ }^{24}$ Em semelhante construção, todos e cada um dos elementos que a compõem, "constituição", "poder", "controle", "direitos", adquire formação precisa para cada situação integradas em um paradigma que sempre tem em jogo o conceito de "segurança" (GUILLÉN LÓPEZ 2016, p. 261 e ss.). Não é possível, portanto, conceber o constitucionalismo e seus conceitos fundacionais sem reparar, por sua vez, no caráter estrutural da segurança e por esta razão ela paira sobre os textos constitucionais, e como o faz, além disso, projetando-se com significados muito diferentes. ${ }^{25}$ Dessa forma, uma das chave ${ }^{26}$ que levaram o constitucionalismo ao seu estágio atual é a forma pela qual combinou o princípio da segurança, e temos indícios suficientes de que ele também será um dos vetores (senão o principal) que lhe dará forma no futuro imediato.

Consideremos, em primeiro lugar, que o Estado moderno, o seu prresuposto histórico indiscutível (e certamente hoje o seu principal fardo para imaginar o constitucionalismo em contextos pós-estatais) nasceu como uma nova estrutura que superava em funcionalidade a poliarquia medieval pela capacidade de proteger os súditos. ${ }^{27}$ Tal segurança não significa, de forma alguma, a

23 Como Cruz Villalón (2017) magnificamente diz: "Se impõem a necessidade de saber, mais imperiosa que nunca, quando chegar o momento e quanto vai atuar, tanto a razão pela qual um bom legal precioso deve ser sacrificado, e que justificaria não ser sacrifício em nenhum caso, sem privar de sua identidade e sua razão para ser forjado comunidades depois de tantos esforços coletivos."

24 "Toute Société dans laquelle la garantie des Droits n'est pas assurée, ni la séparation des Pouvoirs déterminée, n'a point de Constitution."

25 Entre outras coisas a necessidade de harmonizar o impossível enquanto que "poder" é "unidade" e "direito" é "pluralismo".

${ }^{26}$ No glossário do constitucionalismo também teriam entradas destacadas "responsabilidade", "representatividade", "democracia" e "pluralismo".

27 Conforme sempre traz Hobbes (1995, p. 215): "A causa final, o propósito que faz os homens - os quais amam por natureza a liberdade e o domínio sobre os demais - se impõem a si mesmos essas restrições de quando vivem em Estado, é a procura de sua própria conservação, e consequentemente uma vida mais agradável. Quer dizer, os que pretendem sair de uma 
ausência de violência (de modo algum poderia ser pregada durante a vigencia incontestável princípio da soberania), mas a sua canalização, a sua racionalização.

$\mathrm{O}$ estado (como Max Weber ${ }^{28}$ canonicamente aponta) continua a deter um monopólio legítimo sobre a violência, o que significava o controle dos pulsões que fez o homem se comportar como homem com os outros. ${ }^{29}$ A segurança é, no Estado moderno, portanto, uma condição de sua existência e não representa, nem por indício, banir a espada, mas usá-la quando, de acordo com procedimentos cada vez mais elaborados de decisão, é possivel identificar os amigos e os inimigos (exteriores e interiores). $\bigcirc$ Estado Moderno nasce em um meio extremamente hostil, perseguido em seu território e à espreita além fronteiras. ${ }^{30}$ Em ambas as frentes, a violência é entendida como garantia da segurança do Estado, ou seja, a sua existência, a integridade e seu território. A segurança exige assim uma defesa frente ao Estados rivais potencialmente invasores (daí a conexão tradicional entre a segurança e defesa) e a repressão de conflitos internos que enfraqueceriam um poder unitário concebido como a chave deste sistema embrionário e precário do governo de um número cada vez maior de súditos em territorios extensos (no que se refere aos grandes Estados-Nação). Segurança, violência e Estado, aparecem, consequentemente, numa vinculação inexplicável que expressa perfeitamente a ideia de Razão de Estado (MEINECKE, 1983). Certamente, a segurança aqui é apresentada sob a perspectiva objetiva que a destaca como a condição da existência e garantia do sucesso do Estado que a fornece. É de se considerar que se o Estado surge para eliminar a violência extrema entre os sujeitos, e passa a considerar-se que o Estado garantirá a sua própria segurança porque só ele, por definição, é capaz de impor condições que as relações não violentas exigem. $\bigcirc$ Estado usa a segurança reduzindo toda sua vinculação original com os sujeitos individuais.

Ao falarmos sobre os processos cada vez mais formalizados que determinam quando a violência pode e deve ser exercida para dobrar vontades, estamos nos referindo ao Direito como aquele sistema cada vez mais autônomo que está progressivamente permitindo prever as consequências de nossas ações: confiando em nullapoena sine lege; confiar na reparação do dano causado. Em suma, o Direito é concebido como um conjunto normativo articulado através do qual instituições decisórias

situação insuportável de guerra, como mostrado no capítulo 13, são necessárias as paixões naturais dos homens quando não há um poder visível que os mantenha amedrontados e com a ameaça do castigo os obrigue a cumprir suas obrigações e observar as leis descritas nos capítulos 14 e $15 . "$

28 Estado entende-se como um instituto de atividade política contínua, que na medida que seu quadro administrativo mantém com sucesso a reivindicação legítima da coerção física para a manutenção da ordem vigente (WEBER, 1984, p. 43-44).

29 “O homem não é necessariamente o lobo do homem. É algo muito mais perverso: outro homem. Um homem em competição pela vida. Pela vida física e por uma vida melhor, isto é, certo que, enfeitada com bens e vantagens que somente a dominação do meio e sobre os homens. Uma vida, enfim, somente conduzida pela força, cujo exercício é afinar numa realidade insustentável de toda relação interindividual: o poder do homem sobre o homem." (GUILLÉN LÓPEZ, 2016, p. 39). Não esquecendo do pressuposto radicalmente realista de clássicos como Madison (1998, p. 220), desconfiando do Povo: "Mas o que é o governo senão o maior dos censuradores da natureza humana?) Se os homens fossem anjos, o governo não seria necessário." Ou Constant (1828, p. 614), desconfiando do poder: "Toutes les constitutions sont des actes de défiance: car si on croyait que le pouvoir ne fera jamais d'empiétement, nous n'aurions pas besoin de constitutions, ni de chambres, ni de lois répressives."

30 "O dever mais evidente do Estado consiste em velar com eficácia e permanência a segurança do território nacional. Segurança não significa ausência de perigo, pois neste mundo sempre há perigo, mas uma possibilidade razoável de sair a frente em caso de crise. Mas esse é tão somente o mais elementar dos deveres do Estado. Não fará nada senão dedicar-se únicamente à ele, pois se limitando exclusivamente ao dever, não há possibilidade alguma de cumprir." (WEIL, 2014, p. 125, grifo nosso). 
(vontade) e de garantia (razão) ${ }^{31}$ respondem às pretensões recíprocas dos sujeitos a partir de um esquema predeterminado e cognoscível previamente. Este sistema é coativo; ou seja, funda-se em sanções, na capacidade de até mesmo exercer a violência física sobre aqueles que não cumprem a norma. Esta é a maneira pela qual o direito dá segurança: através da previsibilidade relativa de resposta dos poderes públicos frente às nossas ações e reprimindo a conduta daquele que ameaçam a nossa autonomia injustificadamente.

Com a regeneração do constitucionalismo resultante da incorporação generalizada no final do século XVIII da noção de direitos (FIORAVANTI, 2009), a segurança deixa de ser exclusivamente um pressuposto da existência e subsistência do Estado (aspecto objetivo da segurança) ou atributo de um sistema formal de resolução organizada de conflitos, como pode ser o direito. A segurança volta a ser apreciada em seu aspecto subjetivo; como uma tarefa das autoridades públicas e como uma tarefa que se vincula diretamente ao grau de satisfação com a garantia dos direitos a serem reconhecidos aos cidadãos como tal. De fato, o entendimento contemporâneo do conceito de segurança segue sendo tributário de artigos como o $2^{\circ}$ da Declaração dos Direitos do Homem e do Cidadão (1789), segundo o qual: "O objetivo de todas as negociações políticas é a conservação dos direitos naturais e inalienáveis do Homem. Estes direitos são liberdade, propriedade, segurança, e resistência à opressão." ${ }^{2}$

A segurança, sob o ponto objetivo, como um atributo de direito, deve se somar a segurança sob o ponto de vista subjetivo; segurança como respeito da autonomia pessoal de cada um dos sujeitos do direito; segurança como respeito a autonomia pessoal de cada um dos sujeitos de direito; a segurança como o único contexto possível para desenvolver um projeto de vida; ou seja, buscar com liberdade a própria personalidade. A segurança é, deste ponto de vista, o resultado da normalidade, o exercício ordinário de direitos. Realmente, dado o dualismo liberal que apresenta a sociedade isto é, os direitos - como a prioridade, e o Estado - a sujeição - como o secundário, este último só justifica a sua existência na medida em que cumpre a função de garantir o que em termos de termos contemporâneos chamaria, a segurança cidadã, a ordem pública; a única função que se os cidadãos não cedessem, jogaria por terra todo o sistema de direitos e liberdades recém conquistados. Voltamos a ter aquí uma nova evidencia da simbiose entre segurança e Estado. A segurança não é mais apresentada como um caminho para o engrandecimento de um Estado que define o bem, mas para realizar aquilo que o cidadão não pode realizar com base na sua autonomia individual. No paradigma de pré-direitos, a segurança é "para" o Estado; no tempo dos direitos, o Estado é apenas a segurança para os indivíduos. Estado de direito, divisão de poderes, são construções para limitar o poder, garantir os direitos dos cidadãos e permitir-lhes desfrutar com segurança as novas capacidades de ação que alcançaram.

\footnotetext{
31 Clássico o tratamento da dualidade gubernaculum e iurisdictio em Mcilwain (2016).

32 “Não obstante, é necessário pontuar que na língua francesa há dois vocabulários 'sécurité' e 'sûreté' que não tem o mesmo significado, o primeiro se refere à liberdade pessoal enquanto que o seguinte integra o conceito de ordem pública."
} 
Quando a segurançaé percebida desta forma, como um valor resultante doótimo funcionamento do sistema de direitos, é óbvio que ela necessita de uma garantia, porque não se pode pensar que a violência, interior ou exterior, vai desaparecer completamente. A segurança jurídica concebida, obriga assim, a sua proteção e a contemplação de medidas que deverão serem tomadas quando ela estará em perigo. Essas medidas buscam a proteção dos direitos, mas também a salvaguarda do próprio Estado, pressuposto, por sua vez da ordem jurídica que protege os direitos. Como a estrutura estatal já pressupõe o triunfo da ordem, o modelo de proteção da segurança das pessoas é articulado de forma binária: há um modelo comum de paz, em que o direito penal prevê a restrição da liberdade pessoal para aqueles que ferem direitos de terceiros; e um modelo excepcional, exigido para aquelas circunstâncias extraordinárias que podem colocar o estado soberano, mais uma vez, em risco de desaparecimento ${ }^{33}$ (no caso de guerra) ou como uma estrutura falida, em um cenário de pulsões humanas sem controle (a organização da luta pela sobrevivência que é desencadeada por desastres naturais, por exemplo). É normal neste esquema binário que não existem zonas cinzentas entre a normalidade (ordem) e a excepcionalidade (desordem); ${ }^{34}$ entre o ordenamento permanente e provisório. Uma ordem ameaçada de forma permanente gerava um paradoxo que o direito tradicional não tinha resposta. ${ }^{35}$

Todo o exposto contitui o paradigma para observar a tensão tradicional observada entre a segurança e as liberdades. Essa tensão surge, portanto, porque no conceito histórico de segurança estão implicados tanto a segurança do Estado (Salus populi suprema Lex isto) como a segurança das pessoas (aspectos subjetivos da segurança). A segurança contém estes dois elementos supremos e não é difícil conceber (a partir de uma análise puramente realista, não jurídica) que o poder dá lugar à tentação de entender que, em situações de crise, primeiro é o Estado. A inclusão na segurança do paradigma de exceção como mecanismo para a restauração da normalidade pode ser vista dessa perspectiva.

Em resumo: é evidente que a segurança acaba por ser um conceito de enorme densidade constitucional e profunda complexidade, uma vez que é invocado com significados muito diferentes: a segurança como um pressuposto para a existência do Estado e emblema a superação do Estado de natureza; segurança jurídica como certeza e previsibilidade; segurança como um pressuposto de direitos e como limite para o exercício dos direitos; mesmo em alguns ordenamentos, como o francês, a segurança como um direito autêntico. ${ }^{36}$ Muitas caracterizações, mas um elemento em comum: a

\footnotetext{
${ }_{33}$ Interessante como se fala da vida da nação (sic) para justificar a suspenção dos efeitos da Convenção Europeia dos Direitos do Homem (1950) em seu artigo 15.1: "Em caso de guerra ou de outro perigo público que ameace a vida da nação, qualquer Alta Parte Contratante podera tomar medidas que derroguem as obrigacões previstas no presente Convenio na medida estrita em que exiga a situação, e claro que tais medidas não estejam em contradição com outras obrigações contrárias ao Direito Internacional."

34 A normalidade do paradigma reside nos controles aos quais o Estado se submete. As pretensões de omissão que são para os particulares os direitos fundamentais neste momento (GRIMM, 2006, p. 183) obrigam conceber o restante da constituição como uma estrutura para desativar a possibilidade de intervenção negativa. Pelo contrário, esta lógica se altera nos momentos de excepcionalidade definido pelas obrigações de intervenção que estão submetidos os poderes públicos.

35 Nessa lógica cabe entender as teorias de Schmitt de compreender todo o ordenamento sob a sombra da excepcionalidade porque somente a normalidade poderia ser alterada e desconhecida em favor da comunidade de sangue (RUTHERS, 2016).

36 No ordenamento francês se considera como um direito fundamental (apesar da relutância de uma parte da doutrina como Granger (2009), desde a Lei n. 95-73 de 21 de janeiro de 1995 d'orientation et de programmation relative à la sécurité que esta-
} 
segurança é a negação da arbitrariedade; é o limite; a tentativa de domar a soberania absoluta; o controle de poder, seja de instituições ou de poder fátio. O constitucionalismo é inconcebível sem segurança, porque sem segurança não há direitos. Afirma Montesquieu (1979, p. 294): "A liberdade política, num cidadão, é aquela tranquilidade de espírito que provém da opinião que cada um tem da sua segurança; e, para que se tenha essa liberdade, é preciso que o governo seja tal, que um cidadão não possa temer outro cidadão." Portanto, é um contrasenso inadmissível adotar o padrão de falta de segurança como uma desculpa propícia, da excepcionalidade, para erguer novos soberanos absolutos, para justificar a ditadura (como na abordagem de Schmitt). ${ }^{37}$ Esta abordagem que direciona o conteúdo do princípio constitucional de segurança para uma de suas ambitos (a segurança como um instrumento conceitual para a afirmação e exaltação do Estado e instrumento para a purificação daqueles definidos como seu inimigos ${ }^{38}$ ) é profundamente desconhecida dos outros acepções: a segurança das pessoas (ou seja, seus direitos) e a segurança como previsibilidade e controle de direito aplicável (segurança jurídica).

\section{Segurança, constituição e constitucionalismo europeu}

No contexto atual, estamos assistindo a dois fenômenos de diferentes sinais que convertem em uma necessidade absoluta voltar a pensar desde as origens o que significa a segurança. $O$ primeiro se refere aos processos de distribuição territorial do poder que levaram, desde a segunda metade do século XX, tendo o marco europeu como principal referência, a construção de novos modelos supranacionais. Nos encontramos, portanto, num contexto de profunda indefinição; ${ }^{39} \mathrm{em}$ um momento de sucessão de estruturas jurídico-políticas e dos sistemas normativos através dos quais aquelas se manifestam. Considerando a vínculação existencial entre a segurança e Estado, fica evidente como o primeiro dos termos deve ser o último redutos que quer conservar um Estado cada vez mais fraco. ${ }^{40} \mathrm{O}$ Estado-Nação nasceu pela segurança; durante o dualismo liberal o Estado se reduzido à segurança (Estado-Gendarme); no modelo social (Estado-Providência), o Estado gera segurança através da garantia de um conjunto de direitos. A segurança e cada Estado, como é de

\footnotetext{
blece: "La sécurité est un droit fondamental. Elle est une condition de l'exercice des libertés et de la réduction des inégalités. A ce titre, elle est un devoir pour l'Etat, qui veille, sur l'ensemble du territoire de la République, à la protection des personnes, de leurs biens et des prérogatives de leur citoyenneté, à la défense de leurs institutions et des intérêts nationaux, au respect des lois, au maintien de la paix et de l'ordre publics."

37 É uma contradição sempre que temos o constitucionalismo como parâmetro de referência, mesmo que com toda evidência, não é colocado nem sequer em questão nessas páginas. Não é parte do paradigma que manteve Schmitt entre 1933 e 1945, como tem sido amplamente acreditado, demolir o constitucionalismo para iluminar o ordenamento jurídico novo e articulado em torno de Führer como defensor do direito, da Comunidade de sangue como sujeito político e a justificação do Grande espaço (RUTHERS, 2016, p. 121 e ss.).

38 No caso da teoria jurídica nacional-socialista, aqueles que não integram a comunidade de sangue (BRUTHERS, 2016).

39 Novamente sobre a definição de El sueño constitucional. Permito-me remeter o leitor ao resumo mínimo da abordagem dessa obra em Guillén López (2016).

40 Dando lugar a uma disfuncionalidade desde o ponto de vista operativo evidente porque a enorme energia (também desde o ponto de vista conceitual) que é necessária para acometer os desafios da segurança não é não é previsível de estruturas que evidentemente se encontram em declive.
} 
fácil avaliação, declinam de uma forma absolutamente particular como resultado de diferentes experiências históricas. ${ }^{41}$

A sucessão é também, evidentemente apreciável nos sistemas normativos, uma vez que as dos Estados são estruturalmente deslocadas ${ }^{42}$ pelo ordenamento da União, pelo "desenraizamento" e cosmopolita Direito da União que já não se ancora nas magnitudes identitárias do passado, tais como povo, língua, cultura, território; que, portanto, não pode apelar a essa legitimidade de origem, na qual o direito não é uma expressão atual da vontade de uma comunidade existente, mas a vontade de constituir essa comunidade em cada ato normativo. É um direito "fraco" neste sentido, necessitado, porque não pode se apresentar imediatamente blindado com o escudo protetor que outorga a ele ser a expressão com que a vontade nacional decidirá ordenar seu futuro. ${ }^{43}$ Terá de ultrapassar um escrutínio muito mais rigoroso com a única oportunidade que lhe é concedida pelo conceito de legitimidade do exercício. Assim, este direito, da UE - e, por conseguinte, a estrutura que o torna possível - terá sérias dificuldades de legitimar quando os resultados esperados pelos seus destinatários não são alcançados e a frustração irá desencadear consequências negativas para a União e lamentos melancólicos pelo Estado e a soberania que se perdeu (e nunca voltará).

De forma irreversível, o tempo do Estado-Nação passou. As novas estruturas devem prover a segurança que um Estado fraco não pode garantir. $\bigcirc$ novo ordenamento europeu deve atuar neste sentido e sua eficácia dependerá que entre estrutura e ordenamento os meios comunicantes permitem conectar as diferentes legitimações. Como podemos dar qualquer futuro à UE se não fornecer um grau aceitável de segurança e bem-estar para todas as pessoas que nela vivem?

Daí a segunda razão pela qual a reflexão sobre segurança deve ser intensificada. 0 processo de construção da União tem sido, poderíamos dizer, enormemente ingênuo no que se refere às dimensões constitutivas de qualquer nova estrutura jurídico-política que tem pretensões de êxito: a economaa e segurança em seu território. Cabe entender as dificuldades para minar estes elementos de identificação da soberania estatal (creio que apontamos as razões), mas o que não é tão compreensível é que saltos qualitativos, uma vez dados, não contaram com mecanismos que permitiram corrigir possíveis desvios do promissor horizonte de Bruxelas que se desenhava. A União tem se destacado por uma retumbante falta de previsão em parcialmente devida à sua incapacidade de observar realisticamente o contexto econômico e securitário.

No que diz respeito ao aspecto monetário e econômico, tem sido uma constante sinal como a crise que começou em 2008 confirma um vazio retumbante que é preenchido com instrumentos completamente atípicos ao serviço de uma política econômica exclusiva - a austeridade

\footnotetext{
41 Razão que que a segurança supõe como um direito próprio como um dos elementos do conceito de identidade constitucional. A respeito Cruz Villalón (2017).

42 Sobre a dimensão estrutural do princípio da primazia Aguilar Calahorro (2015).

43 Um modelo de Direito em vinculação necessária com a Nação que representa, por exemplo, no artigo 3 da Constituição Espanhola (1812): "A soberania reside essencialmente na Nação, e pertence a esta exclusivamente, o direito de estabelecer suas leis fundamentais."
} 
como mecanismo para a salvação do Euro - que deixa em apuros uma grande parte dos objetivos econômicos e sociais reconhecidos nos Tratados constitutivos e na Carta dos Direitos Fundamentais da União Europeia (BALAGUER CALLEJÓN, 2013; OFFE, 2013). Destacamos, no entanto, que as políticas econômicas e monetárias nunca foram exclusivamente resguardadas pelos Estados, mas houve sempre uma comunicação entre as esferas nacionais e internacionais e, sobretudo, as áreas público-privadas para que os Estados pudessem contar com recursos econômicos suficientes que lhes permitiram empreender os seus projetos internos ou externos. Em suma, Estado e Economia nunca foram tão indissolúvelmente e ligados como Estado e Segurança.

A UE também não contava com a necessidade de articular diretamente ou propor soluções para uma ameaça tão urgente como o terrorismo de 9/11. Em diferentes Estados-Membros, foram observadas as devastadoras consequências das suas ações, e o medo está presente em todos eles, este sentimento muito complexo de transformação em políticas racionais; este sentimento que é geralmente usado por demagogos para propor soluções simplistas e falsas e que tendem a tornar a União um bode expiatório. Para a UE, o terrorismo é um grande desafio, na medida em que a abertura das fronteiras internas que integram como uma das suas marcas de identidade elimina o controle por intermédio dos fluxos migratórios - no sentido tradicional que une o inimigo aos outros ${ }^{44}$ - $\operatorname{como}$ o porta de entrada dos jihadistas para os nossos Estados. É assim que a visão da UE como causa de instabilidade ou como uma experiência fracassada que não pode substituir o Estado-Forte. A União é fraca (se não perversa de acordo com o menos escrupuloso de seus críticos), burocrática, jurídica, contra os Estados-Nação (com mais ênfase no segundo substantivo versus o primeiro). Se trata capsiosamente de desenhar uma "União-mecanismo inútil" frente à "Nação-organismo vivo", histórico, natural, essencial, sujeito capaz de se proteger. É observável que as forças políticas que, na UE (tanto nos Estados do norte como no sul) atacam o projeto europeu, e têm como uma das suas principais linhas ideológicas as pretensões de travar a imigração a qual está diretamente ligada com a insegurança. O cenário para a UE é, nesse sentido, devastador: visto como culpado, não é capaz de chegar a soluções porque a competência sobre a segurança segue estando atribuída aos EstadosMembros ${ }^{45}$ que, em raras ocasiões, apelam à sua incapacidade, porque a UE não consegue manter as suas fronteiras externas ilesas e elimina as fronteiras internas (quando não tenta forçar mesmo moralmente para os Estados acolhamos os refugiados) (ABELLÁN, 2017).

No que se refere aos terroristas, o certo é que estão comprovando pela primeira vez os efeitos devastadores de agir sobre os direitos, bens individuais e coletivos que não são adstritos unicamente a uma estrutura jurídico-política que controla exclusivamente seu território, senão sobre modelos

\footnotetext{
44 Esquecendo que muitos dos terroristas são nacionais do Estado em que cometem seus crimes.

45 Art. 4.2 Tratado da União Europeia (1992): "A União respeitará a igualdade dos Estados-Membros perante os Tratados, bem como a sua identidade nacional, inerente às suas estruturas políticas e constitucionais fundamentais, também em relação à autonomia local e regional. Respeitará as funções essenciais do Estado, especialmente aquelas que visam garantir sua integridade territorial, manter a ordem pública e salvaguardar a segurança nacional. Em particular, a segurança nacional continuará a ser da exclusiva responsabilidade de cada Estado-Membro."
} 
constitucionais que cederam grande parte de sua soberania em uma organização supranacional. Em outras palavras, aqueles que são mortos por Daesh são cidadãos franceses, espanhóis, alemães... e europeus; e é esta última identidade, a mais frágil, a que pode ceder, produzindo o desmoronamento inexorável desta grande experiência política que tem sido a União. Grande triunfo para a estratégia do terrorismo, seja o que for, que é sempre "quanto pior, melhor", o elogio da destruição como força criadora. ${ }^{46}$

É, pois, óbvio para aqueles que escrevem isto que os Estados e a UE têm a nova responsabilidade perante eles, a enorme tarefa de reforçar o projeto constitucional da Europa. Nenhuma outra solução é plausível. E para o fazer, deve transitar para uma política econômica e securitária comum, porque nada poderá parar os que trabalham para seu fim, se os cidadãos não vêem melhorias no seu bem-estar e segurança.

Pensar, portanto, sobre a segurança, a nível europeu, é a única forma; pensar na segurança na conscientização da ambivalência desse conceito, transitando sobre os diferentes significados que o tornaram um elemento chave e definidor do estado constitucional; ${ }^{47}$ partindo da necessária conciliação entre seus perfis objetivos e subjetivos; Considerando as tragédias às quais as palavras "crise" ou "excepcionalidade" estão conduzindo sistemas tecnicamente requintados; sabendo, em suma, que, no momento atual, as respostas constitucionais nacionais devem ser consideradas respostas parciais no âmbito de uma política europeia de segurança e de direitos.

Procede, pois, reelaborar uma narrativa constitucional sobre segurança como princípio constitucional; como princípio já da ordem constitucional pós-nacional; como eixo no qual sintetizar as experiências históricas estatais à serviço de uma nova realidade constitucional destinada pela força da razão para não ceder às fronteiras: o constitucionalismo ${ }^{48}$.

\section{Referências}

ABELLÁN, Lucía. El reparto de refugiados en la UE termina con un cumplimiento ínfimo. El País, 27 sept. 2017. Disponível em: https://elpais.com/internacional/2017/09/26/actualidad/1506453916_188550.html. Acesso em: 12 out. 2019.

AGUILAR CALAHORRO, Augusto. La dimensión constitucional del principio de primacía. Madrid: Thomson: Reuters: Aranzadi, 2015.

BALAGUER CALLEJÓN, Francisco. "Crisis económica y crisis constitucional en Europa". REDC, n. 98, 2013.

BALAGUER CALLEJÓN, Francisco. Fuentes del Derecho I. Principios del ordenamiento constitucional. Madrid: Tecnos, 1991.

\footnotetext{
46 Demonstração evidente de como é fácil para os manipuladores da linguagem acabar destruindo o senso comum quando são anuladas as bases intelectuais que permitem um sujeito comum resistir.

47 Não é apropriado, por exemplo, recorrer a imagens triviais e mal ajustadas, como a da balança, para resolver as tensões entre o que chamei de dimensões objetivas e subjetivas da segurança. Nesse sentido, Cerdá Guzman (2017).

48 Sempre uma proposta numa boa - e afortunadamente -medida utópica (CABO MARTÍN, 2004, p. 47-56).
} 
BALAGUER CALLEJÓN, Francisco; GARCÍA, Estanislao Arana (coord.). El constitucionalismo universal desde las constituciones parciales nacionales e internacionales: siete tesis. Libro homenaje al profesor Rafael Barranco Vela, [S. l.], v. 1, 2014.

BALAGUER CALLEJÓN, Francisco. "La contribución de Peter Häberle a la construcción del Derecho Constitucional Europeo". Revista de derecho constitucional europeo, Granada, n. 13, p. 189-208, 2010. Disponível em: https://www.ugr.es/ redce/REDCE13/articulos/07FBalaguer.htm\#13. Acesso em: 12 out. 2019.

BALAGUER CALLEJÓN, Francisco. "Las dos grandes crisis del constitucionalismo frente a la globalización en el Siglo XXI". Revista de derecho constitucional europeo, Granada, n. 30, 2018. Disponível em: https://www.ugr.es/ redce/REDCE30/articulos/02_F_BALAGUER.htm. Acesso em: 12 out. 2019.

BELTRÁN DE FELIPE, Miguel; GONZÁLEZ GARCÍA, Julio V. Las sentencias básicas del Tribunal Supremo de los Estados Unidos de América. 2. ed. Madrid: CEPC, 2006.

CABO MARTÍN, Carlos de. "El elemento utópico, ingrediente cultural del constitucionalismo". In: BALAGUER CALLEJÓN, Francisco (coord.). Derecho constitucional y cultura: Estudios en homenaje a Peter Häberle. Madrid: Tecnos, 2004.

CERDÁ GUZMAN, Carolina. "Los Derechos fundamentales y la lucha contra el terrorismo: Francia bajo Estado de emergencia". ReDCE, n. 27, enero/jun. 2017. Disponível em: https://www.ugr. es/ redce/REDCE27/articulos/02_CERDA.htm. Acesso em: 12 out. 2019.

CONSTANT, Benjamin. Discours. A la Chambre des députés. Archives parlementaires, 2e série, t. 53, p. 614, 2 mai. 1828.

CONSTITUIÇÃO DOS ESTADOS UNIDOS. 1789.

CONSTITUÇÃO ESPANHOLA. 1812.

CONVENÇÃO EUROPEIA DOS DIREITOS DO HOMEM. 1950.

CRUZ VILLALÓN, Pedro. "Entre proporcionalidad e identidad: las claves de la excepcionalidad en el momento actual". Revista de Derecho constitucional europeo, n. 27, enero-junio de 2017. Disponível em: https://www.ugr.es/ redce/REDCE27/articulos/11_CRUZ.htm. Acesso em: 12 out. 2019.

\section{DECLARAÇÃO DOS DIREITOS DO HOMEM E DO CIDADÃO. 1789.}

FIORAVANTI, Maurizio. Los derechos fundamentales, Apuntes de historia de las Constituciones. Madrid: Trotta, 2009.

GRANGER, Marc-Antoine. Existe-t-il um droit fondamental à la sécurité? RSC, 2009.

GRIMM, Dieter. "El futuro de la Constitución". In: GRIMM, Dieter. Constitucionalismo y Derechos Fundamentales. Madrid: Trotta, 2006. p. 208.

GUILLÉN LÓPEZ, Enrique. Noticia de Libros: Juan Luis Requejo Pagés, "El Sueño Constitucional". ReDCE, Oviedo: KRK Ediciones, n. 26, jul./dic. 2016. Disponível em: https://www.ugr.es/ redce/ REDCE26/articulos/13_libro_REQUEJO.htm. Acesso em: 12 out. 2019. 
HÄBERLE, Peter. Rechtsvergleichung im Kraftfeld des Verfassungsstaates. Methoden und Inhalte, Kleinstaaten und Entwicklungsländer. Duncker \& Humblot, Berlin, p. 27-44, 1992.

HOBBES, Thomas. Leviatan. Tradução: Carlos Melliz. Madrid: Alianza Editorial: Círculo de Lectores, 1995.

JONAS, Herder. El principio de responsabilidad: Ensayo de una ética para la civilización tecnológica. Barcelona: Editorial Herder:1995.

JUDT, Tony. Postguerra. Madrid: Taurus, 2008.

LÖSING, Norbert. "Estado de derecho, seguridad jurídica y desarrollo económico". Anuario iberoamericano de justicia constitucional, n. 6, p. 274, 2002.

MADISON, James. El Federalista. México: Fondo de Cultura Económica, 1998.

MCILWAIN, Charles Howard. Constitucionalismo antiguo y moderno. 2. ed. Madrid: Centro de Estudios Políticos y Constitucionales, 2016.

MEINECKE, Friedrich. La idea de la razón de Estado en la Edad Moderna. Madrid: CEC, 1983.

MONTESQUIEU, Charles. De l'Esprit des lois. De la Constitución de Inglaterra. Libro XI, Capítulo VI. París: Flammarion, 1979. p. 294.

MOSER JONES, Marian; BAYER, Ronald. "Paternalism\&Its Discontents. Motorcycle Helmet Laws, Libertarian values, and Public Health". American Journal of Public Health, v. 97, n. 2, Feb. 2007.

OFFE, Claus. "Europa acorralada". REDC, n. 98, 2013.

ORTEGA Y GASSET, José. "Prólogo" de La decadencia de occidente de Oswald Spengler. Madrid: Austral, 2011).

PERNICE, Ingolf. Multilevel constitutionalism in the European Union. Walter Hallstein Institute Papers, n. 5, 2002.

POPPER, Karl. La sociedad abierta y sus enemigos. Barcelona: Paidos, 1957.

RUTHERS, Bernd. Derecho degenerado. Teoría jurídica y juristas de cámara en el Tercer Reich. Madrid: Marcial Pons, 2016.

TRATADO DA UNIÃO EUROPEIA. 1992.

WEIL, Simone. Echar raices. Madrid: Trotta, 2014. 